\title{
Effect of Temperature on Production of Ochratoxin A by Aspergillus niger in Orange Juice
}

\author{
Andreana Marino, Caterina Fiorentino, Francesca Spataro, and Antonia Nostro \\ Dipartimento di Scienze del Farmaco e dei Prodotti per la Salute, Università di Messina, Polo Annunziata, 98168 Messina, Italy \\ Correspondence should be addressed to Andreana Marino; anmarino@unime.it
}

Received 31 October 2013; Accepted 19 December 2013; Published 28 January 2014

Academic Editor: Andreimar Martins Soares

Copyright (C) 2014 Andreana Marino et al. This is an open access article distributed under the Creative Commons Attribution License, which permits unrestricted use, distribution, and reproduction in any medium, provided the original work is properly cited.

This challenging study was carried out to evaluate the temporal production of ochratoxin A (OTA) by Aspergillus niger ATCC 16404 and wild type A. niger AM at different temperatures in fresh squeezed orange juice (Citrus sinensis [L.] Osbeck cv Tarocco). Each strain, inoculated into the filtered orange juice, was incubated at $4{ }^{\circ} \mathrm{C}, 20^{\circ} \mathrm{C}$, and $26^{\circ} \mathrm{C}$ for 28 days. In the juice, at $26^{\circ} \mathrm{C}$ and $20^{\circ} \mathrm{C}$, the concentration of A. niger ATCC 16404 increased by more than $2 \log _{10}$ up to the 21 st day. At $4^{\circ} \mathrm{C}$ it remained constant. The microbial load of $A$. niger AM decreased at all temperatures. At $26^{\circ} \mathrm{C}$, the maximum OTA accumulation found was $3.44 \mathrm{ng} / \mathrm{mL}$ on the 21st day for A. niger ATCC 16404 and $8.44 \mathrm{ng} / \mathrm{mL}$ on the 7th day for A. niger AM. The OTA synthesis seemed to be an intrinsic strain-dependent mechanism. A. niger ATCC 16404 produced OTA in accordance with the higher temperatures and the biomass concentrations, whereas A. niger AM produced the toxin at all temperatures regardless of its biomass. These results showed that fresh orange juice contaminated with Aspergillus niger aggregate strains may contain OTA levels.

\section{Introduction}

The market of organic citrus fruit has increased during the last few years because of consumer demand for healthy food products [1]. Most of the citrus arrives at the market in the form of processed products, such as single-strength orange juice and frozen juice concentrates [2]. Before pasteurization, fruit juices contain a microbial load representative of the organisms normally found on fruits during harvest plus postharvest contaminants. Pasteurization rids juice of pathogens and other heat-sensitive microbes. However, if the original load is too high and/or the pasteurization process is inadequate, some microorganisms might survive and subsequently cause spoilage and possibly illness if the surviving organisms are virulent [3]. Therefore, these products, especially nonpasteurized single-strength juice, are not free of microbiological spoilage problems [2, 4]. Moulds and yeasts tolerate high-osmotic and low $\mathrm{pH}$ conditions and grow at refrigeration temperatures [2]. The mould growth may result in several kinds of food-spoilage: off-flavours and discoloration; moreover, if the contaminating microorganisms are pathogens, it could also cause human illness $[3,5,6]$. In many tropical countries the fresh nonpasteurized orange juice is sold at all public shops along the roadside [7]. The most important aspect of mould spoilage of foods is, however, the formation of mycotoxins. Small amounts of mycotoxins remain in mould cells, as most of them are excreted in the foods. Since most of the mycotoxins are very resistant to physical and chemical treatment, a rule of thumb exists: once the mycotoxins are in the food, they stay there during processing and storage $[6,8,9]$.

Ochratoxin A (OTA) was originally described as a metabolite of Aspergillus ochraceus Wilhem and was found soon after from several related Aspergillus species [10, 11]. The origin of OTA in cool and temperate climates is generally attributed to Penicillium verrucosum, whereas in warm temperate and tropical zones it is commonly associated with $A$. ochraceus and the black aspergilli $[12,13]$. The significance of black aspergilli as toxin-producing fungi has changed since the evidence that they can produce mycotoxins that are considered a risk for human and animal health emerged $[14,15]$. OTA has been widely detected in cereals, 
spices, some drinks such as coffee, and wines [11, 16-19]. European Regulation lays down the maximum levels of the said substance for cereals, cereal products, raisins, roasted coffee, wine, grape juice, spices, liquorice, and food for children. The tolerable weekly intake (TWI) of ochratoxin A is $120 \mathrm{ng} / \mathrm{kg}$ body weight [20]. OTA has been shown to be nephrotoxic, hepatotoxic, teratogenic, and immunotoxic to several species of animals and is known to cause kidney and liver tumors in mice and rats. In humans, it has been related to Balkan endemic nephropathy, although this hypothesis has not been completely demonstrated [21]. According to the International Agency for Research on Cancer, OTA is possibly carcinogenic to humans (Group 2B) [22].

The economically most important OTA producers belong to Aspergillus sections Circumdati and Nigri [23, 24]. The black aspergilli are spread worldwide and occur on a great variety of substrates, including spoiled fruits, vegetables, and decaying vegetation in the fields [25]. In addition, they can contaminate agricultural products at different stages including preharvest, harvest, processing, and handling. Most of them are encountered as storage moulds on plant products [26]. Section Nigri (black aspergilli) is the main group responsible for OTA detected in grapes, must, and wines $[27,28]$. The aim of this work was to establish OTA production by Aspergillus niger at different temperatures in fresh squeezed orange juice.

\section{Materials and Methods}

2.1. Fungal Strains and Growth Conditions. Aspergillus niger ATCC 16404 and Aspergillus niger AM aggregate strains isolated from rotted citrus fruit were inoculated on malt extract agar (MEA; Oxoid, Basingstoke, UK) at $25^{\circ} \mathrm{C}$ for 7 days. Conidia suspension was obtained by harvesting spores and suspending them in sterile distilled water containing $0.005 \%$ of Tween 80 (Difco; Becton Dickinson, Milan, Italy). The final concentration of the spores was standardized to $1 \times 10^{7}$ spores/mL using a spectrophotometer (Perkin Elmer, Lambda 15, MA, USA).

2.2. Preparation of Orange Juice. Tarocco oranges (Citrus sinensis [L.] Osbeck) were obtained from local orchards and were used after a short storage period at $4^{\circ} \mathrm{C}$ (no longer than 1 week). Oranges were of typical commercial maturity. Before each experiment the fruits were disinfected by dipping in a $\mathrm{NaOCl}$ 0.5\% (Carlo Erba, Milan, Italy) solution for $1 \mathrm{~min}$ and in a $70 \%$ ethanol solution for $2 \mathrm{~min}$, rinsed with sterile distilled water and air-dried at room temperature.

The disinfected oranges were peeled and squeezed with a domestic juicer. The juices were centrifuged at $6000 \mathrm{rpm}$ for $15 \mathrm{~min}$ at $15^{\circ} \mathrm{C}$. The supernatant was filtered twice through a Whatman \# 2 filter paper chart and subsequently again filtered through a $0.45 \mu \mathrm{m}$ sterile filter (Millipore, Bedford, USA) into sterile bottles under aseptic conditions.

2.3. Determination of Toxigenic Potential of Fungi by ELISA. The preliminary study was carried out in vitro using a basic orange juice medium agar (OJMA) and Yeast Extract Sucrose agar (YES; Oxoid) as medium control [29]. OJMA was composed of $10 \%(\mathrm{v} / \mathrm{v})$ orange juice in sterile distilled water, five-fold agar, $\mathrm{pH}$ 3.5. Petri plates containing $20 \mathrm{~mL}$ of each medium were needle-inoculated centrally with the suspensions described above and incubated at $26^{\circ} \mathrm{C}$ for 7 days. Then, three agar plugs ( $5 \mathrm{~mm}$ diameter) were removed from each colony. The plugs were placed in vials to which $1 \mathrm{~mL}$ of a mixture of methanol/formic acid $(25: 1, \mathrm{v} / \mathrm{v})$ (Carlo Erba) was added. After $60 \mathrm{~min}$, the extract was filtered through a Whatman \# 1 filter paper. OTA accumulation was determined in every treatment using a commercial ELISA Immunoscreen OCHRA kit (Tecna S.r.l. Trieste, Italy). Direct competitive enzyme-linked immunosorbent assays were performed as described earlier [29]. Absorbance was measured at $450 \mathrm{~nm}$ with a microplate reader (BioRad Model 550, Laboratories Milano, Italy). According to the manufacturer's description, the detection limit was $0.05 \mathrm{ng} / \mathrm{mL}$. Each assay was performed in triplicate.

2.4. Challenge Test. The orange juice samples $(50 \mathrm{~mL})$ were contaminated with $5 \mathrm{~mL}$ of the above-described standardized spores and incubated at $26^{\circ} \mathrm{C}, 20^{\circ} \mathrm{C}$, and $4^{\circ} \mathrm{C}$. The viable counts were determined at different intervals of time $(7,14$, 21 , and 28 days). Serial dilutions of each sample were made and aliquots of $1 \mathrm{~mL}$ were added into tubes containing molten MEA (Oxoid), mixed and poured into plates. The viable counts were expressed as spores per $\mathrm{mL}$. Each viable count was performed in triplicate.

2.5. Determination of OTA in Orange Juice. OTA extraction was carried out as previously described [29]. Five $\mathrm{mL}$ of each orange juice sample was extracted with five $\mathrm{mL}$ of $1 \mathrm{M}$ hydrochloric acid (Carlo Erba) and $10 \mathrm{~mL}$ of dichloromethane (Carlo Erba) each time. The mixture was shaken for $15 \mathrm{~min}$ and centrifuged for $8 \mathrm{~min}$ at $9000 \mathrm{rpm}$ at $4^{\circ} \mathrm{C}$. Two phases: a lower solvent and an upper aqueous were formed. Sodium bicarbonate solution ( $\mathrm{pH}$ 8.1) (Carlo Erba) was added to the solvent phase. After centrifugation at $9000 \mathrm{rpm}$ for $8 \mathrm{~min}$, the aqueous phase was collected and centrifuged again to separate it from any residual solvent. The aqueous phase was taken and diluted twice with bicarbonate solution (Carlo Erba). OTA in samples was determined in triplicate using OCHRA kit as described above.

2.6. Statistical Treatment of Results. For the fungi counts the obtained results were fitted to simple linear regression using Microsoft Excel 2000. The experimental data of OTA concentration was interpolated using a nonlinear regression analysis. Analyses of variance (ANOVA) for individual differences were used to compare cellular viability and OTA production over time. Correlations between fungi counts and OTA production were estimated using the Karl Pearson coefficient of correlation. The statistical variables were evaluated with Mathcad 2001i Professional (MathSoft Engineering \& Education, Inc.). 


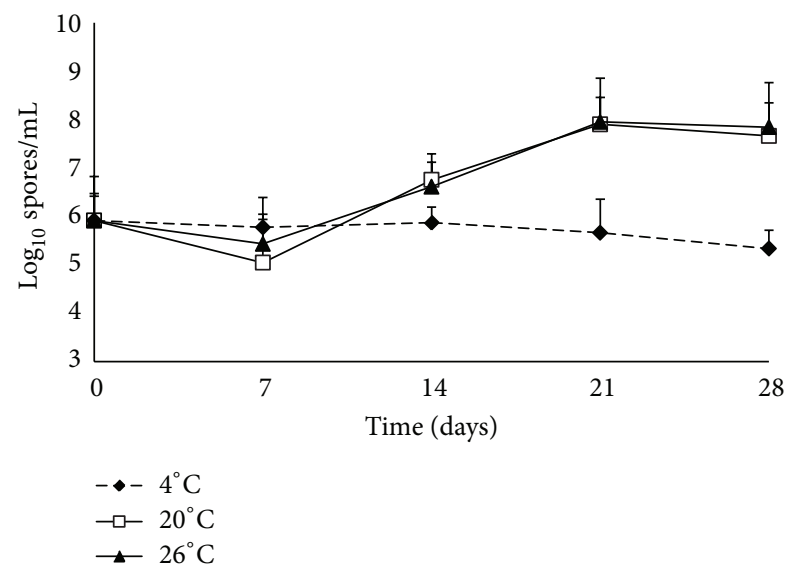

Figure 1: Effect of temperature on the growth of A. niger ATCC 16404 (A. n.) in orange juice. Mean values \pm standard error.

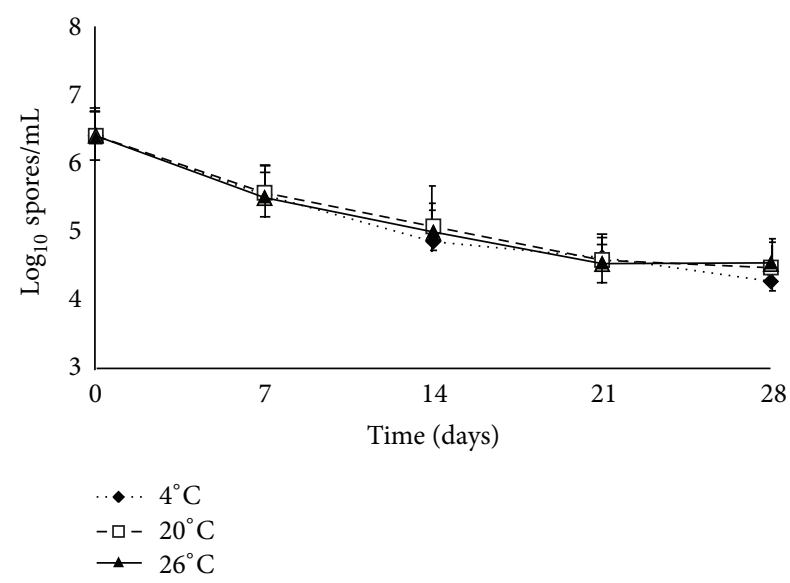

FIgURE 2: Effect of temperature on the growth of A. niger AM (A. $n$. $\mathrm{AM})$ in orange juice. Mean values \pm standard error.

\section{Results and Discussion}

Both strains showed mycelial growth and OTA production (up to $5 \mathrm{ng} / \mathrm{g}$ ) after 7 days of incubation at $26^{\circ} \mathrm{C}$ on OJMA. The cellular viability curves for A. niger ATCC 16404 and A. niger AM/temperature treatments on orange juice are shown in Figures 1 and 2, respectively. A. niger ATCC 16404 in juice incubated at $26^{\circ} \mathrm{C}$ and $20^{\circ} \mathrm{C}$, after a latency period of about 7 days, increased in population by more than $2 \log _{10}$ on the 21st day, after which the number of cells remained constant. At $4^{\circ} \mathrm{C}$, the strain maintained the initial concentration for up to 15 days and then decreased. The initial concentration of $A$. niger AM decreased gradually of about $2 \log _{10}$ until the 21st day at all temperatures. Thereafter, the populations remained constant. The cellular viability of $A$. niger ATCC 16404 was statistically significant compared with that of $A$. niger AM $(P \geq 0.1)$.

The mean OTA concentrations produced by $A$. niger ATCC 16404 and $A$. niger AM at each temperature and incubation time in the juice are summarized in Figures 3 and 4 , respectively. The OTA concentration produced by $A$. niger

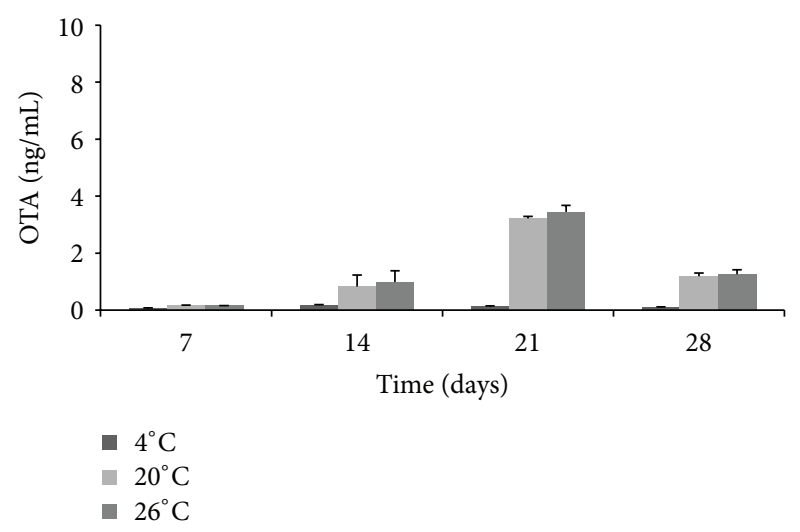

FIgURE 3: OTA concentrations produced by A. niger ATCC 16404 in orange juice at different temperatures. Mean values \pm standard error.

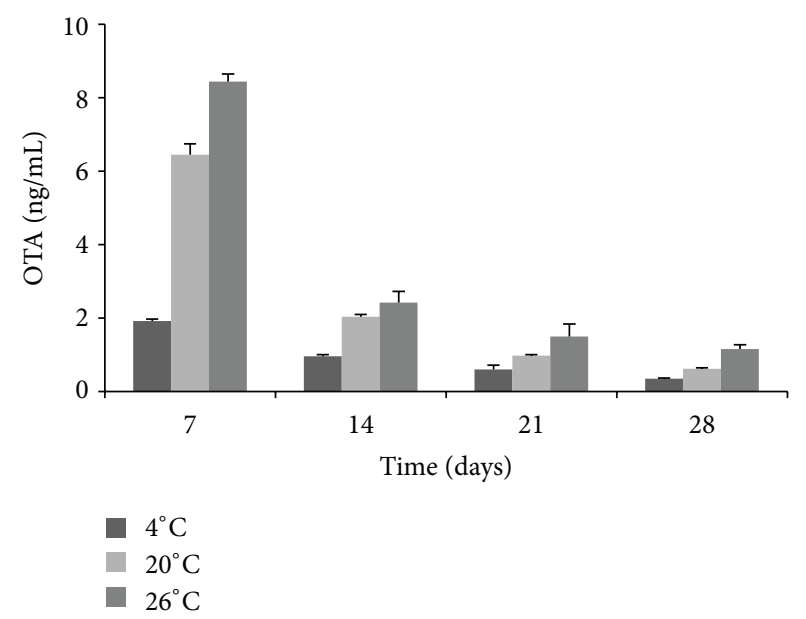

FIGURE 4: OTA concentrations produced by A. niger AM in orange juice at different temperatures. Mean values \pm standard error.

ATCC 16404 at $26^{\circ} \mathrm{C}$ and $20^{\circ} \mathrm{C}$ increased until the 21 st day and then with time diminished. The correlation coefficient $\left(R^{2}=0.99\right)$ justified the significant correlation between biomass and OTA synthesis. At $4^{\circ} \mathrm{C}$ the concentration levels were very low during the assay. OTA production by $A$. niger AM rose until the 7 th day at all temperatures; subsequently, the concentrations rapidly decreased with time. Maximum OTA accumulation was produced at $26^{\circ} \mathrm{C}$. At $4^{\circ} \mathrm{C}$ the mould was able to produce the toxin throughout the observation period. OTA production by A. niger ATCC 16404, at the higher temperatures, was significantly higher compared with that of $A$. niger AM by day 21 of incubation $(P \geq 0.1)$. OTA produced by $A$. niger AM was synthesized in a shorter time (7 days) and in a higher concentration than that by $A$. niger ATCC 16404 at all temperatures $(P \geq 0.1)$.

The source of microbial contamination of fruit juices has not been fully established, but the surfaces of citrus fruits are known to harbour microbial populations which can potentially contaminate the juices. Blood orange juice features such as nutrients, low $\mathrm{pH}$, and water activity seem to favour OTA production while temperature seems to be 
the main factor influencing toxin production [29-33]. In this study the increase of temperature favored the growth and OTA synthesis of $A$. niger ATCC 16404. After a long latency period, at higher temperatures, A. niger ATCC 16404 increased in population and produced toxin in the orange juice until the 21st day. A. niger ATCC 16404 synthesized OTA in accordance with the higher temperatures and biomass concentrations in orange juice. Instead, the temperature did not affect the growth of $A$. niger AM, but rather the production of the toxin. A. niger AM produced most of the toxin at the higher temperatures within 7 days. Plant and food substrates are colonized by a diverse mycoflora that competes for nutrients and space in this context; mycotoxins could be envisaged as competitive factors, particularly in conditions of environmental stress [34-36]. In orange juice, according to our results, it appears that A. niger ATCC 16404 enters into an extended lag phase in which it begins to produce the toxin and reaches maximum production at the growth phase. Instead, A. niger AM seems to produce the toxin early on at all temperatures regardless of the biomass concentrations. It must be emphasized, for further investigation, that maximum amounts of OTA were found after a few days from the contamination by A. niger AM and at all temperatures. This behavior seems to be an intrinsic mechanism that is strain dependent. A possible explanation could be mycostasis. This has been envisaged as a mechanism by which propagules are protected from spontaneous germination in the absence of a substrate to be colonized [37]. After reaching peak production, the concentration of toxin gradually decreased over time probably due to the detoxification of ochratoxin A caused by A. niger [38]. Some authors have suggested that the strains can remove and assimilate the phenylalanine moiety from the OTA molecule because other nitrogen sources in the culture media are insufficient $[39,40]$. A carboxypeptidase secreted by the $A$. niger strain could decompose OTA to ochratoxin $\alpha$ and phenylalanine. Experiments with Aspergillus species showed a nearly complete conversion to ochratoxin $\alpha$ within 5 days and after 7 days ochratoxin $\alpha$ was further degraded [38, 41]. Despite the economic importance of citrus juices, there are few reports investigating OTA production associated with Aspergillus niger-aggregate group [29, 42, 43]. These results showed how fresh orange juice contaminated with Aspergillus niger aggregate strains may contain OTA levels. Further studies on other environmental strains of $A$. niger should be carried out to better understand the production of OTA in orange juice.

\section{Conflict of Interests}

The authors declare that there is no conflict of interests regarding the publication of this paper.

\section{References}

[1] R. Porat, A. Daus, B. Weiss, L. Cohen, E. Fallik, and S. Droby, "Reduction of postharvest decay in organic citrus fruit by a short hot water brushing treatment," Postharvest Biology and Technology, vol. 18, no. 2, pp. 151-157, 2000.
[2] C. R. Arias, J. K. Burns, L. M. Friedrich, R. M. Goodrich, and M. E. Parish, "Yeast species associated with orange juice: evaluation of different identification methods," Applied and Environmental Microbiology, vol. 68, no. 4, pp. 1955-1961, 2002.

[3] V. H. Tournas, J. Heeres, and L. Burgess, "Moulds and yeasts in fruit salads and fruit juices," Food Microbiology, vol. 23, no. 7, pp. 684-688, 2006.

[4] C. McNamee, F. Noci, D. A. Cronin, J. G. Lyng, D. J. Morgan, and A. G. M. Scannell, "PEF based hurdle strategy to control Pichia fermentans, Listeria innocua and Escherichia coli k12 in orange juice," International Journal of Food Microbiology, vol. 138, no. 1-2, pp. 13-18, 2010.

[5] J. Chelkowski, Cereal Grain. Mycotoxins, Fungi and Quality in Drying and Storage, Elsevier, Amsterdam, The Netherlands, 1991.

[6] O. Filtenborg, J. C. Frisvad, and U. Thrane, "Moulds in food spoilage," International Journal of Food Microbiology, vol. 33, no. 1, pp. 85-102, 1996.

[7] D. P. Mahale, R. G. Khade, and V. K. Vaidya, "Microbiological analysis of street vended fruit juices from Mumbai city, India," International Journal of Food Safety, vol. 10, pp. 31-34, 2008.

[8] F. J. Cabañes, M. R. Bragulat, and G. Castellá, "Ochratoxin A producing species in the genus Penicillium," Toxins, vol. 2, no. 5, pp. 1111-1120, 2010.

[9] A. E. Kapetanakou, J. N. Kollias, E. H. Drosinos, and P. N. Skandamis, "Inhibition of A. carbonarius growth and reduction of ochratoxin A by bacteria and yeast composites of technological importance in culture media and beverages," International Journal of Food Microbiology, vol. 152, no. 3, pp. 91-99, 2012.

[10] A. Ciegler, "Bioproduction of ochratoxin A and penicillic acid by members of the Aspergillus ochraceus group," Canadian Journal of Microbiology, vol. 18, no. 5, pp. 631-636, 1972.

[11] E. Pardo, S. Marín, V. Sanchis, and A. J. Ramos, "Impact of relative humidity and temperature on visible fungal growth and OTA production of ochratoxigenic Aspergillus ochraceus isolates on grapes," Food Microbiology, vol. 22, no. 5, pp. 383389, 2005.

[12] M. L. Abarca, F. Accensi, M. R. Bragulat, and F. J. Cabañes, "Current importance of ochratoxin A-producing Aspergillus spp," Journal of Food Protection, vol. 64, no. 6, pp. 903-906, 2001.

[13] F. Accensi, M. L. Abarca, and F. J. Cabañes, "Occurrence of Aspergillus species in mixed feeds and component raw materials and their ability to produce ochratoxin A," Food Microbiology, vol. 21, no. 5, pp. 623-627, 2004.

[14] M. L. Abarca, F. Accensi, J. Cano, and F. J. Cabañes, "Taxonomy and significance of black aspergilli," Antonie van Leeuwenhoek, vol. 86, no. 1, pp. 33-49, 2004.

[15] V. Ostry, F. Malir, and J. Ruprich, "Producers and important dietary sources of ochratoxin A and citrinin," Toxins, vol. 5, pp. 1574-1586, 2013.

[16] B. Zimmerli and R. Dick, "Ochratoxin A in table wine and grape-juice: occurrence and risk assessment," Food Additives and Contaminants, vol. 13, no. 6, pp. 655-668, 1996.

[17] P. Noonim, W. Mahakarnchanakul, K. F. Nielsen, J. C. Frisvad, and R. A. Samson, "Isolation, identification and toxigenic potential of ochratoxin A-producing Aspergillus species from coffee beans grown in two regions of Thailand," International Journal of Food Microbiology, vol. 128, no. 2, pp. 197-202, 2008.

[18] E. Petzinger and A. Weidenbach, "Mycotoxins in the food chain: the role of ochratoxins," Livestock Production Science, vol. 76, no. 3, pp. 245-250, 2002. 
[19] M. L. Chiotta, M. L. Ponsone, D. M. Sosa, and M. Combina, "Biodiversity of Aspergillus section Nigri populations in Argentinian vineyards and ochratoxin A contamination," Food Microbiology, vol. 36, no. 2, pp. 182-190, 2013.

[20] Anon, "Maximum levels for certain contaminants in foodstuffs," European Union, Regulation, (EC) no. 1881/2006, 2006.

[21] V. Sorrenti, C. di Giacomo, R. Acquaviva, I. Barbagallo, M. Bonanno, and F. Galvano, "Toxicity of ochratoxin A and its modulation by antioxidants: a review," Toxins, vol. 5, no. 10, pp. 1742-1766, 2013.

[22] IARC, Some Naturally Occurring Substances: Food Items and Constituents, Heterocyclic Aromatic Amines and Mycotoxins, vol. 56 of IARC Monographs on the Evaluation of Carcinogenic Risks of Chemicals to Humans, IARC, Lyon, France, 1993.

[23] R. A. Samson, E. S. Hoekstra, and J. C. Frisvad, Introduction to Food and Airborne Fungi, Centraalbureau voor Schimmelcultures, Utrecht, The Netherlands, 7th edition, 2004.

[24] J. C. Frisvad, U. Thrane, and R. A. Samson, "Mycotoxin producers," in Food Mycology. A Multifaceted Approach to Fungi and Food, J. Dijksterhuis and R. A. Samson, Eds., pp. 135-159, CRC Press, Boca Raton, Fla, USA, 2007.

[25] L. R. Beuchat, Food and Beverage Mycology, Van Nostrand Reinhold, New York, NY, USA, 2nd edition, 1987.

[26] G. Perrone, A. Susca, G. Cozzi et al., "Biodiversity of Aspergillus species in some important agricultural products," Studies in Mycology, vol. 59, no. 1, pp. 53-66, 2007.

[27] F. J. Cabañes, F. Accensi, M. R. Bragulat et al., "What is the source of ochratoxin A in wine?" International Journal of Food Microbiology, vol. 79, no. 3, pp. 213-215, 2002.

[28] P. Battilani, A. Pietri, T. Bertuzzi, L. Languasco, P. Giorni, and Z. Kozakiewicz, "Occurrence of ochratoxin A-producing fungi in grapes grown in Italy, Journal of Food Protection, vol. 66, no. 4, pp. 633-636, 2003.

[29] A. Marino, A. Nostro, and C. Fiorentino, "Ochratoxin A production by Aspergillus westerdijkiae in orange fruit and juice," International Journal of Food Microbiology, vol. 132, no. 2-3, pp. 185-189, 2009.

[30] N. Bellí, S. Marín, V. Sanchis, and A. J. Ramos, "Influence of water activity and temperature on growth of isolates of Aspergillus section Nigri obtained from grapes," International Journal of Food Microbiology, vol. 96, no. 1, pp. 19-27, 2004.

[31] N. Bellí, A. J. Ramos, V. Sanchis, and S. Marín, "Incubation time and water activity effects on ochratoxin a production by Aspergillus section Nigri strains isolated from grapes," Letters in Applied Microbiology, vol. 38, no. 1, pp. 72-77, 2004.

[32] A. Esteban, M. L. Abarca, M. R. Bragulat, and F. J. Cabañes, "Effects of temperature and incubation time on production of ochratoxin A by black aspergilli," Research in Microbiology, vol. 155, no. 10, pp. 861-866, 2004.

[33] V. H. Tournas and E. Katsoudas, "Mould and yeast flora in fresh berries, grapes and citrus fruits," International Journal of Food Microbiology, vol. 105, no. 1, pp. 11-17, 2005.

[34] N. Magan and D. Aldred, "Post-harvest control strategies: minimizing mycotoxins in the food chain," International Journal of Food Microbiology, vol. 119, no. 1-2, pp. 131-139, 2007.

[35] M. Jurado, P. Marín, N. Magan, and M. T. González-Jaén, "Relationship between solute and matric potential stress, temperature, growth, and FUM1 gene expression in two Fusarium verticillioides strains from Spain," Applied and Environmental Microbiology, vol. 74, no. 7, pp. 2032-2036, 2008.
[36] P. Marín, N. Magan, C. Vázquez, and M. T. González-Jaén, "Differential effect of environmental conditions on the growth and regulation of the fumonisin biosynthetic gene FUM1 in the maize pathogens and fumonisin producers Fusarium verticillioides and Fusarium proliferatum," FEMS Microbiology Ecology, vol. 73, no. 2, pp. 303-311, 2010.

[37] R. C. Cooke and J. M. Whipps, Ecophysiology of Fungi, Blackwell Scientific Publications, London, UK, 1993.

[38] J. Varga, K. Rigó, and J. Terén, "Degradation of ochratoxin A by Aspergillus species," International Journal of Food Microbiology, vol. 59, no. 1-2, pp. 1-7, 2000.

[39] J. Téren, J. Varga, Z. Hamari, E. Rinyu, and F. Kevei, "Immunochemical detection of ochratoxin A in black Aspergillus strains," Mycopathologia, vol. 134, no. 3, pp. 171-176, 1996.

[40] J. Varga, K. Rigó, C. Lamper, J. Téren, and G. Szabó, "Kinetics of ochratoxin a production in different Aspergillus species," Acta Biologica Hungarica, vol. 53, no. 3, pp. 381-388, 2002.

[41] J. Varga, Z. Péteri, K. Tábori, J. Téren, and C. Vágvölgyi, “Degradation of ochratoxin A and other mycotoxins by Rhizopus isolates," International Journal of Food Microbiology, vol. 99, no. 3, pp. 321-328, 2005.

[42] G. Riesenfeld, I. Kirsch, and S. Weissman, "Detection and quantitation of aflatoxin B1 in orange juice by SOS-chromotest," Food Additives and Contaminants, vol. 2, no. 4, pp. 253-257, 1985.

[43] S. K. Varma and R. A. B. Verma, "Aflatoxin B1 production in orange (Citrus reticulata) juice by isolates of Aspergillus flavus link," Mycopathologia, vol. 97, no. 2, pp. 101-104, 1987. 

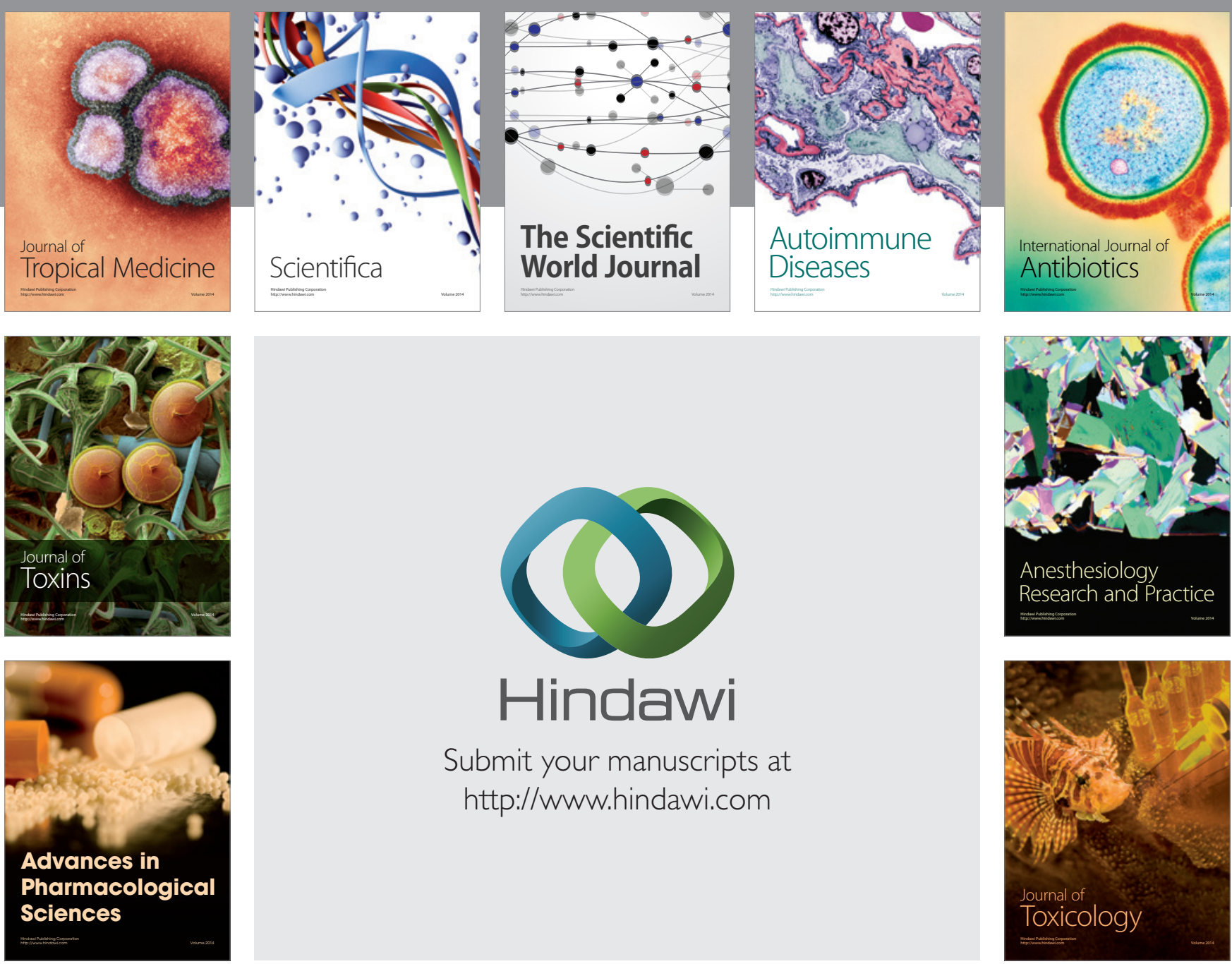

\section{Hindawi}

Submit your manuscripts at

http://www.hindawi.com
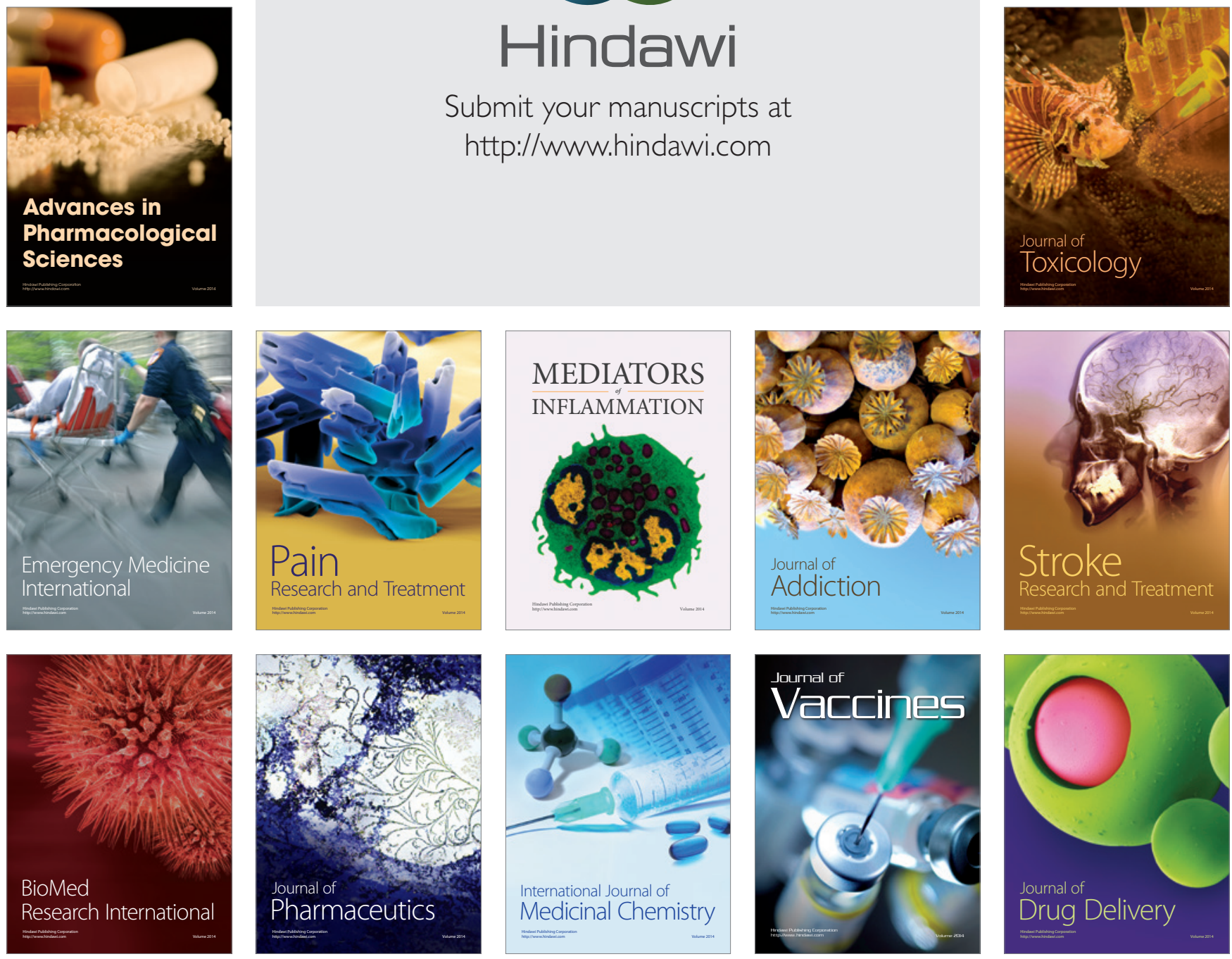